\title{
Inconstitucionalidade do exercício de competências privativas do cargo de auditor fiscal da Receita Estadual por ocupantes do cargo de gestor fazendário
}

Celso Antônio Bandeira de Mello*

O SINDICATO DOS AUDITORES FISCAIS DA RECEITA ESTADUAL, FISCAIS E AGENTES FISCAIS DE TRIBUTOS DO ESTADO DE MINAS GERAIS - SINDIFISCO/MG expõe-nos os fatos abaixo relatados, acosta documentos e, à vista deles, formula a seguinte

\section{Consulta}

1. De acordo com a Lei $n^{\circ}$ 6.763, de 26 de dezembro de 1975, do estado de Minas Gerais, a teor de seu art. 201, §1ㅇ․ "Compete exclusivamente aos Auditores Fiscais da Receita Estadual, aos Agentes Fiscais de Tributos Estaduais e aos Fiscais de Tributos Estaduais o exercício das atividades de fiscalização e de lançamento do crédito tributário". Também no anexo II, subitem II.1 a que se refere o art. 4º da Lei Estadual nº 15.464, de 13 de janeiro de 2005, estão mencionadas tais atribuições dos referidos servidores e ali qualificadas como sendo de competência "privativa" deles.

Inversamente, aos gestores fazendários (que historicamente tiveram outras denominações) competem tão só atividades de menor qualificação, nos termos do anexo II, subitem II.2, a que se refere o art. $4^{\text {o }}$ da mesma Lei Estadual no 15.464 , de 13 de

* Graduado em ciências jurídicas e sociais pela Pontifícia Universidade Católica de São Paulo (PUC-SP) (1959). Advogado. Sócio do Escritório Bandeira de Mello e Grapella Advogados Associados. Professor titular e emérito da PUC-SP. Possui larga experiência na área de direito, com ênfase em direito administrativo. 
janeiro de 2005, e "não privativas de Auditor Fiscal de Tributos Estaduais", como expressamente referido no preceptivo em causa. Assim, são de sua alçada: "desenvolver atividades preparatórias à ação fiscalizadora, sob supervisão do Auditor Fiscal da Receita Estadual”, "auxiliar o Auditor Fiscal da Receita Estadual no desempenho de suas atribuições privativas" (letras $b$ e $c$ do mencionado subitem II.2).

Eis, pois, que o grau de responsabilidade e a complexidade das atribuições de cada qual destes cargos - auditor fiscal e gestor fazendário - diferem significativamente, já que os últimos têm a seu cargo, como indicado, apenas atividades inferiores às que assistem aos primeiros.

“Os concursos públicos para aceder a um e outro destes cargos evidentemente são distintos e com graus de complexidade diferentes": maiores para os cargos de auditor fiscal e menores para os cargos de gestor fazendário. Correlatamente, os vencimentos dos primeiros são bem mais elevados que os dos segundos, ou seja, os destes últimos correspondem a aproximadamente $35 \%$ da remuneração dos auditores fiscais.

Pretende-se, agora, por via de um projeto denominado "Projeto para o Incremento da Arrecadação" unificar as atribuições de uns e de outros, de maneira que os atuais gestores fazendários, cujos cargos passariam a ser denominados de "analistas fiscais da Receita Estadual" seriam, sem concurso público, investidos em competência mais complexa e elevada do que aquela que ora corresponde a seus cargos. Isto é, viriam a ser agraciados com a competência para "constituir mediante lançamento, o crédito tributário, aplicar penalidades e arrecadar tributos", atividades que, conforme dito, são, por lei, cometidas privativamente e exclusivamente aos auditores fiscais.

É em vista dessa pretensão que se formula a seguinte indagação:

É constitucional a inclusão, pela via indicada, dos atuais gestores fazendários, sob a nova denominação de analista fiscal da Receita Estadual, em atribuições que presentemente correspondem em caráter exclusivo e privativo aos auditores fiscais ou tal proceder viola o princípio do concurso público, as disposições constitucionais pertinentes, a Súmula nº 685, do STF, e ofende abertamente o que neles se contempla, com prejuízo inclusive para a moralidade administrativa?

À indagação, respondo nos termos que se seguem.

\section{Parecer}

1. "Todos são iguais perante a lei", diz o caput do art. 5o, que abre o título sobre os direitos e garantias fundamentais arrolados na Constituição. Se assim é, 
a fortiori, todos são iguais perante a administração, pois a função desta é cumprir fielmente os comandos legais. O princípio da isonomia é um mandamento absolutamente básico no Estado de direito. Ademais, é sobre a igualdade que se assenta a ideia de república, ou seja, res publica: coisa de todos. Nele, se traduz a aspiração e o propósito que inspirou a queda do absolutismo. Recorde-se que o lema da Revolução Francesa era "Liberté, égalité, fraternité".

Justamente porque a igualdade é um preceito fundamental que corresponde a uma das colunas mestras do Estado de direito e da república, suas exigências presidem-lhe todos os institutos e, por vezes, ao contemplá-los, a Lei Magna faz mesmo referência clara a imposições que dela decorrem. Assim, ao exigir no art. 37, XXI, licitação para aquisição de bens, obras ou serviços, está contemplando uma aplicação concreta do referido princípio. Mas, talvez, a mais expressiva dessas aplicações concretas especificamente mencionadas resida no inciso II do mesmo artigo, porque se reporta à própria organização do aparelho estatal. Reza o preceptivo em questão:

a investidura em cargo ou emprego público depende de aprovação em concurso público de provas ou de provas e títulos, de acordo com a natureza e a complexidade do cargo ou emprego, na forma prevista em lei, ressalvadas as nomeações para cargo em comissão declarado em lei de livre nomeação e exoneração.

2. Tão cauteloso foi o texto em seu propósito de assegurar integralmente a mais plena aplicação da igualdade no acesso aos cargos e empregos públicos e sua subsequente ocupação que não se contentou em exigir o concurso de provas ou provas e títulos. Para evitar que, por vias transversas, fosse possível aceder a eles sem cabal comprovação de que havia sido reclamada habilitação compatível de todos os candidatos, qualificou as exigências demandando que fossem estabelecidas de acordo com a natureza e a complexidade do cargo.

Essa parte do dispositivo faz a demonstração mais cabal possível de que a Lei Magna, salvo para cargos em comissão, não tolera que um cargo público seja ocupado por alguém que não haja demonstrado em concurso habilitação "especificamente para ele", isto é, que não tenha se submetido à prova na qual haja comprovado com bom sucesso aptidão para a natureza e complexidade dos encargos correspondentes ao cargo ou emprego em questão.

Percebe-se, pois, que além do princípio da igualdade, há outro bem jurídico que a Constituição aí se propõe a realizar: a certeza possível de que irá se equipar com servidores verdadeiramente habilitados, os mais competentes que pode encontrar, para bem cumprir as funções que lhes serão demandadas. Então, de par com o intento de render a devida submissão ao princípio da igualdade, concorre 
um segundo desiderato no inciso "subcomento" do art. 37, também ele, perfeitamente reconhecível: o de pugnar para que sejam selecionados os servidores mais capazes, mais preparados, mais aptos a bem cumprir os cometimentos previstos para o cargo a ser preenchido. Nisto, o que se estampa é o propósito inerente a toda e qualquer organização, qual, o de aparelhar-se para tentar produzir o melhor, o mais adequado a seus fins, projeto obviamente afinado com o princípio da "eficiência", encarecido na cabeça do art. 37.

Vê-se, portanto, que o preceptivo em questão é feraz em implicações, é rico em propósitos, apresentando-se como defensor de objetivos altamente prezáveis, por serem muito caros ao Estado de direito. Daí que é necessário aturado precato no exame de situações que tragam consigo o preenchimento de cargos públicos para aferir-se se neles estão, ou não, sendo respeitados integralmente os intentos reconhecíveis no inciso II do art. 37 da Lei Magna.

Eis, pois, que os concursos públicos são constituídos, então, em vista do tipo e do nível de qualificação que corresponde aos cargos postos em certame. Assim, quando alguém obtém sucesso em concurso e vem a ser provido no correlato cargo, haverá, dessarte, revelado aptidão para ele e não para algum outro diverso, suprível ao cabo de concurso diferente e, eventualmente, com exigências distintas no que concerne à qualificação necessária para disputá-lo. Logo, a habilitação demonstrada em concurso é válida "tão só e unicamente para o cargo inicial da carreira a que corresponde" ou para o cargo de classe singular, se disto se tratar.

Ao superar outros concorrentes, a supremacia que o candidato tenha demonstrado em confronto igualitário com os demais só faz prova de primazia no que respeita a disputantes de cargo daquela tipologia e natureza. Evidentemente, "não comprova que também a obteria se estivesse a disputar cargo diverso, para o qual outros seriam os concorrentes cujos atributos de preparo e conhecimentos haveriam de ser, então, correlatos à espécie de cargo posto em certame".

3. Segue-se que haveria violação do princípio da igualdade se o titular de cargo de dada tipologia, atributivo de competências para certas atividades e carreira, viesse a ser encaixado, fosse por qualquer meio, em cargo de outra identidade, compreensivo de competências diferentes daquelas de seu cargo de origem.

Sobre isso, deixamos anotado em obra teórica (Regime dos servidores da administração direta e indireta. 3. ed. rev., atual. e ampl. São Paulo: Malheiros, 1995, p. 55), nos seguintes termos:

Como este [o concurso público] é sempre específico para dado cargo, encartado em carreira certa, quem nele se investiu não pode depois, sem novo concurso público, ser trasladado para cargo de natureza diversa ou de outra carreira melhor retribuída ou de encargos mais nobres e elevados. 
Este nefando expediente a que se alude foi algumas vezes adotado, no passado, sob a escusa de corrigir "desvios de funções" ou com a nomenclatura esdrúxula de "transposição de cargos". Corresponde a uma burla manifesta do concurso público que permite a candidatos que ultrapassaram apenas concursos singelos, destinados a cargos de modesta expressão - e que se qualificaram tão somente para eles - venham a aceder, depois de aí investidos, a cargos outros, para cujo ingresso se demandaria sucesso em concursos de dificuldades muito maiores, disputados por concorrentes de qualificação bem mais elevada.

Em outra obra (Curso de direito administrativo. 27. ed. São Paulo: Malheiros, 2010, p. 281-282), apostilamos:

O que a Lei Magna visou com o concurso público foi, de um lado, ensejar a todos iguais oportunidades de disputar cargos ou empregos na administração direta e indireta. De outro lado, propôs-se a impedir tanto o ingresso sem concurso, ressalvadas as exceções previstas na Constituição, quanto obstar que o servidor habilitado para cargo ou emprego de determinada natureza viesse depois a ser agraciado com cargo ou emprego permanente de outra natureza, pois esta seria uma forma de fraudar a razão de ser do concurso público.

De resto, o próprio egrégio Supremo Tribunal Federal já se manifestou de forma cortante ao respeito, consagrando seu reiterado entendimento firme na Súmula no 685 , de acordo com a qual: “É inconstitucional toda modalidade de provimento que propicie ao servidor investir-se, sem prévia aprovação em concurso público destinado ao seu provimento, em cargo que não integra a carreira na qual anteriormente investido".

Seriam certamente violadoras da Constituição as chamadas "transposições de cargo", em que alguém concursado e nomeado para determinado cargo é depois integrado em cargo diverso, exigente de habilitações distintas. Com efeito, a aptidão que demonstrou e a disputa que entreteve com outros candidatos foram concernentes a cargo ou emprego de certa natureza e não de outra. Assim, o sucesso que obteve no concurso que efetuou não o credencia para cargo de qualificação diversa, nem garante que, na disputa deste último, sobrepujaria outros candidatos, se o confronto se desse, como teria que ser, entre concorrentes avaliados nos termos das provas e dos títulos aferidores da capacitação específica requerida para o correspondente cargo ou emprego.

4. Será irremissivelmente viciado - e nulo por inconstitucional - qualquer expediente utilizado para ensejar que servidores públicos venham a se integrar em 
cargos de carreiras caracterizadas por atribuições distintas e mais nobres do que as que correspondiam as carreiras dos cargos de origem.

De um lado, afrontaria o objetivo de assegurar ao poder público a vantagem de preencher seus cargos com os mais habilitados a exercê-los entre todos os que comprovaram possuir a qualificação normativamente exigida para a disputa. Deveras, com o comportamento profligado estar-se-ia confiando esses cargos a quem não participou de disputa pública para ocupá-los e, dessarte, não foi confrontado com outros concorrentes que por eles se interessariam. Portanto, estaria outorgando-os a quem sequer comprovou habilitação bastante para ocupá-los e muito menos habilitação superior a outros interessados.

É óbvio, outrossim, que a fraude à Constituição existiria, do mesmo modo, ainda que estes resultados proibidos fossem produzidos através do expediente de transformação, fusão ou integração de classes ou carreiras. Como visto, o que a Constituição não quer são resultados contrapostos a seus comandos. Proibidos estes, não se tornarão lícitos pelo fato de haver-se usado a via tal ou qual para neles aportar.

5. Finalmente, importa dizer que a inconstitucionalidade em questão existiria, do mesmo modo, ainda quando os servidores a serem ubicados em carreira estranha possuam, nessa ocasião, a escolaridade ou titulação profissional para ela requerida. Também é irrelevante quanto a isto a circunstância de já a possuírem quando do ingresso em sua própria carreira ou de haverem-na obtido ulteriormente.

Em quaisquer desses casos persiste o fato - que é o relevante na matéria - de haverem se concursado para cargo de certa carreira e não de outra. Com efeito, na comprovação efetiva do concurso, demonstraram aptidão para integrar determinados cargos insertos em determinada carreira, isto é, capacitação para certo plexo de atribuições, mas não o demonstraram em relação a outro plexo de atribuições.

De outro lado, como já se observou, a supremacia obtida o foi em relação a concorrentes cujas aptidões estavam balizadas pelo concurso que fizeram. Donde nada assegura que alcançariam a mesma prevalência se a disputa tivesse se ferido entre candidatos mensurados por outro gabarito demandado em concurso composto com diferente nível de exigência. Ao superar outros concorrentes, a supremacia que o candidato tenha demonstrado em concorrência igualitária com os demais só faz prova de primazia no que respeita a disputantes de cargo daquele mesmo nível de atribuições. Evidentemente, não comprova que também a obteria se estivesse a disputar cargo diverso, para o qual outros seriam os concorrentes cujos atributos de preparo e conhecimentos haveriam de ser correlatos à espécie de cargo posto em certame e correspondentes ao nível de qualificação exigido para poder disputá-lo.

Segue-se que haveria violação ao princípio da igualdade se o titular de cargo de dada tipologia, atributivo de competências para certas atividades e carreira, 
viesse a ser encaixado, fosse por qualquer meio, em cargo de outra identidade, compreensivo de competências diferentes daquelas de seu cargo de origem. Esse vício apareceria com evidência ainda mais indiscutível quando a escolaridade específica (ou título profissional) exigível para o cargo a ser ocupado fosse diverso ou de nível maior do que o requerido para o cargo de origem, mas, pelas razões expostas, ante a distinta compostura dos respectivos concursos, "existiria mesmo que o nível de escolaridade demandado fosse equivalente para ambas as carreiras".

6. É claro, então, que seriam certamente violadoras da Constituição quaisquer providências por via das quais alguém concursado e nomeado para determinado cargo viesse depois a ser integrado em cargo diverso, exigente de habilitações distintas.

Acresce que fazê-lo, tanto mais por meios transversos, como os referidos, denuncia conduta afrontosa a outro valor consagrado constitucionalmente na cabeça do art. 37: o importantíssimo princípio da moralidade, cuja violação, aliás, enseja a propositura de ação popular, a teor do art. 5ํ, LXXIII, pois é claro que o uso de expedientes para contrariar a Constituição é gravoso ao princípio citado.

Então, prover tais cargos por qualquer via que não fosse a de um concurso específico para eles, de um lado, afrontaria o objetivo de assegurar ao poder público a vantagem de preenchê-los com os mais habilitados a exercê-los, entre todos os que comprovaram possuir a qualificação normativamente exigida para a disputa. Deveras, com o comportamento profligado estar-se-ia confiando esses cargos a quem não participou de disputa pública para ocupá-los e, dessarte, não foi confrontado com outros concorrentes que por eles se interessariam. Portanto, estaria outorgando-os a quem sequer comprovou habilitação bastante para ocupá-los e muito menos habilitação superior a outros interessados.

Todas essas averbações, em rigor óbvias porque assentadas diretamente em preceptivos constitucionais explícitos e claríssimos, oferecem imediata e inobjetável solução aos questionamentos da consulta, como a seguir se indica.

7. Conforme expõe a consulta e esclarecem os documentos acostados, os atuais auditores fiscais da Receita Estadual, fiscais e agentes fiscais de tributos estaduais do estado de Minas Gerais, a teor, quer do art. 201, $\$ 1^{\circ}$, da Lei $n^{\circ}$ 6.763, de 26 de dezembro de 1975, daquele estado, quer do anexo II, subitem II.1, $a$, a que se refere o art. $4^{\circ}$ da Lei Estadual n⿳0 15.464, de 13 de janeiro de 2005, exercem funções que lhes são exclusivas, no dizer do primeiro texto mencionado, ou privativas, conforme expressão do segundo deles.

Reza o mencionado art. 201, §1을 "Compete exclusivamente aos Auditores Fiscais da Receita Estadual, aos Agentes Fiscais de Tributos Estaduais e aos Fiscais de Tributos Estaduais o exercício das atividades de fiscalização e de lançamento do crédito tributário". 
Lê-se no anexo II, subitem II.1, $a$, a que se refere o art. $4^{\circ}$ da Lei $\mathrm{n}^{\mathrm{o}} 15.464$, que ao auditor fiscal da Receita Estadual (Afre) compete: “Em caráter privativo: a) constituir, mediante lançamento, o crédito tributário, aplicar penalidades e arrecadar tributos; $[\ldots]^{\prime \prime}$.

8. Diversamente, aos gestores fazendários (que historicamente tiveram outras denominações) competem tão só atividades de menor qualificação, nos termos do

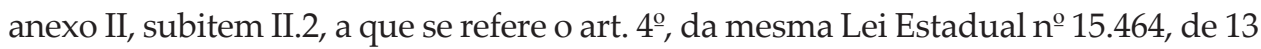
de janeiro de 2005. Ali se menciona que são da alçada do gestor fazendário (Gefaz): "Em caráter geral, as atribuições relativas às atividades inerentes à competência da SRE não privativas do Auditor Fiscal de Tributos Estaduais, especialmente [...]".

Assim, são de sua alçada, como se lê no subitem II.2, alínea $b$, do anexo II referido pelo mencionado art. $4^{\mathrm{o}}$ da lei estadual em apreço: "desenvolver atividades preparatórias à ação fiscalizadora, sob supervisão do Auditor Fiscal da Receita Estadual, inclusive em regime de plantão no Posto de Fiscalização; [...]". E , a teor da alínea c: "auxiliar o Auditor Fiscal da Receita Estadual no desempenho de suas atribuições privativas; [...]".

É, pois, meridianamente claro que os cargos em questão possuem atribuições distintas, sendo que as de auditor fiscal são de maior complexidade, de nível mais elevado e privativas dele, ao passo que as de gestor fazendário são de menor complexidade, de nível menor, se exercem sob supervisão dos primeiros, em caráter auxiliar deles, sendo-lhes vedado exercer as privativas do auditor.

Por isso, como seria óbvio e, de resto, consoante expõe a consulta, os concursos para gestor fazendário são de menor teor de complexidade e dificuldade do que os concursos para auditor fiscal.

Informa a consulente que pretende agora, por via de um projeto denominado "Projeto para o Incremento da Arrecadação" compartilhar as atribuições de uns e de outros, passando os atuais gestores fazendários a serem chamados de "analistas fiscais da Receita Estadual". Ficariam investidos na competência para "constituir mediante lançamento, o crédito tributário, aplicar penalidades e arrecadar tributos", atribuições mais complexas e elevadas do que aquela que ora corresponde a seus cargos e que, conforme dito, são por lei cometidas privativa e exclusivamente aos auditores fiscais. Finalmente, em consequência dessa manobra, os atuais "gestores" viriam, sem concurso público, a ser agraciados com cargos mais elevados, de competências mais nobres, complexas e privativas dos outros cargos aos quais se acede originariamente por meio de certames mais difíceis e cujas remunerações, compreensivelmente, são bem maiores.

Obviamente, a teor de tudo quanto até então se disse, percebe-se que se trata de propósito manifestamente inconstitucional, que agride a talho de foice preceitos da Carta Magna que, como se viu, são fundamentais e se encontram na própria raiz de objetivos básicos do Estado de direito e da República, pois se incompatibi- 
lizam em abertas e publicadas com o princípio da igualdade e com as disposições atinentes ao concurso público.

9. Isto tudo posto e considerado, à indagação da consulta respondo:

É obviamente inconstitucional a inclusão, pela via indicada, dos atuais gestores fazendários, sob a nova denominação de analista fiscal da Receita Estadual, em atribuições que presentemente correspondem em caráter exclusivo e privativo aos auditores fiscais. Tal proceder viola, à escala vista, o princípio do concurso público, as disposições constitucionais pertinentes, a Súmula no 685 , do STF, e ofende, à generala, o que neles se contempla, com prejuízo, inclusive, para a moralidade administrativa.

São Paulo, 18 de maio de 2010

Celso Antônio Bandeira de Mello

OAB-SP nํㅜ 11.199 